\title{
La influencia de Estados Unidos en México
}

\author{
Josefina Zoraida Vázquez \\ EL COLEGIO DE MÉXICO
}

Ensayo sobre las distintas formas culturales y modelos
políticos estadunidenses que han tenido impacto en México.

G

stados Unidos ha sido la primera potencia mundial a lo largo de casi todo el presente siglo y al cual ha impreso el sello de su cultura y estilo de vida. El impacto de su presencia ha sido definitivo aun en aquellas partes en donde el nacionalismo o la ideología lo han combatido, y es comprensible que si eso ha sucedido en el mundo en general, haya afectado también a su vecino del sur.

La contigüidad con Estados Unidos ha modelado el curso de la historia mexicana y ha favorecido el desarrollo de vínculos estrechos entre las dos naciones, pero también han existido algunos que lo han estorbado. En el norte predominó hasta hace poco la cultura blanca, anglo- sajona y protestante (WASP) y en el sur la católica mestiza, lo que ha tenido que enfrentar dos formas de percibir el mundo y la vida. Los del norte, "recién llegados", "modernos", con una pragmática actitud vital, sin raíces en el nuevo mundo que los impulsó a moverse hacia el oeste, conscientes de sus intereses y metas. Los del sur, enraizados a través del mestizaje con las culturas indígenas del nuevo mundo y orgullosos de su pasado. Protestantismo y catolicismo no han sido meros accidentes, sino que han originado maneras peculiares de calibrar la vida y han originado una serie de prejuicios que no dejan de chocar cuando se encuentran. De un lado, según los del norte, están los salvados y del otro. los 


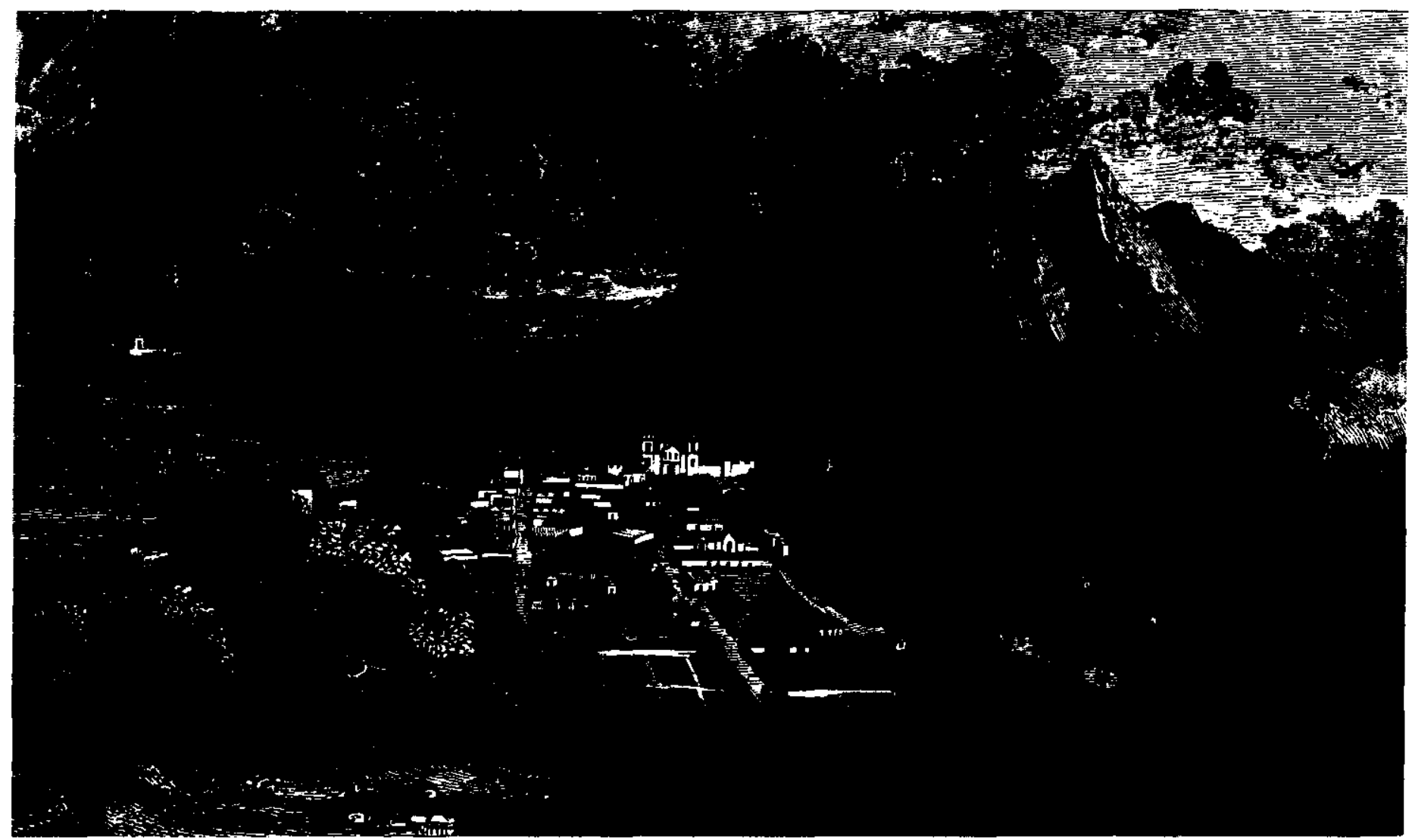

condenados, y la actitud de conocedores del camino no los ha abandonado desde el momento en que Colton Mather decidió aprender español, según alardeaba en quince dias, para escribir $L a$ fe del cristiano enviada a los españoles, folletito destinado a salvarlos, y que estaba acompañado de la idea negativa sobre los otros habitantes del continente, crueles, perezosos "corruptos y afeminados, por ejemplo", según expresaría Timothy Pickering en 1799. Del otro lado la resignada confianza que dio el catolicismo a sus habitantes, conjugada con la Ilustración, resultó en una actitud confiada y optimista en que los males profundos se resolverían fácilmente con sólo la independencia y la colonización de las tierras.

Y puesto que Estados Unidos se independizó antes y tuvo éxito en el establecimiento de sus instituciones políticas, fue natural que los líderes independen- tistas mexicanos volvieran su mirada hacia aquel país en busca de ayuda, aunque con tantos acontecimientos posteriores encontraron eco en sólo un puñado de americanos y se toparon con un muro de contención en la mayoría que, por ignorancia, temieron lo desconocido y se defendieron despreciándolos. Así, para John Adams era tan absurdo hablar de "establecer democracias entre los pájaros, las bestias y los peces es igual a establecerlas entre los hispanoamericanos". Y si consideramos que a tal idea iban a sumarse las ambiciones territoriales, entenderemos lo dramático y difícil de las primeras relaciones.

No obstante, al entusiasmo libertario de Henry Clay correspondió un lazo

${ }^{1}$ Arthur Preston Whitaker, Tbe United States and tbe Independence of Latin America, The Johns Hopkins Press, Baltimore, 1941, p. 37. 
profundo en ideales, y la primera etapa de la vida nacional mexicana estaría permeada de una admiración por su vecino, al que consideró un modelo respetable. Al momento de elaborar una primera constitución, los mexicanos ansiosos de ampliar sus elementos de juicio publicaron las dos constituciones francesas, las dos estadunidenses, los artículos de El Federalista y los ensayos de Paine. Los admiradores de las instituciones republicanas predominaban sobre los monárquicos, sin embargo la Constitución estadunidense influyó muy poco en la mexicana, pues habiendo participado algunos de los líderes constitucionalistas más activos en la elaboración de la Constitución española de 1812, ésta fue la influencia decisiva. No obstante, en ese momento los ideales de democracia y libertad ligaron con auténtica espontaneidad a algunos estadunidenses con muchos mexicanos. Y no era una admiración irreflexiva, sino enterada y crítica como lo muestra el libro de Lorenzo de Zavala (1833) Viaje a los E.U. de Norteamérica.

Los acontecimientos hacían difícil mantener el optimismo de los primeros momentos dado el expansionismo estadunidense, y el trauma de las pérdidas del Tratado de Guadalupe haría difícil para los liberales mexicanos mantener al sistema estadunidense como modelo. Pero amenazado el republicanismo durante los años cuarenta y cincuenta del siglo pasado, los liberales que vivieron en el exilio en Nueva Orleans continuaron creyendo en la validez de su modelo y pensaron que la mejor defensa de México sería la imitación de sus instituciones ya que, con excepción de la esclavitud, seguían admirándolas. El triunfo coronó al final el esfuerzo liberal aunque tampoco esta vez tuvo gran ayuda de su vecino que, ocupado en su gue- rra civil, declaró su neutralidad ante la intervención francesa en México. Al término de aquélla, el gobierno estadunidense presionó a Napoleón III para retirarse, lo que provocaría un acercamiento momentáneo.

El programa liberal estaba definido: educación, ferrocarriles y colonización. Lo más exitoso fue la construcción ferrocarrilera que antes de terminar el siglo acercó a México a Estados Unidos ya que las líneas más importantes unieron Laredo, El Paso y Nogales con la ciudad de México. Muchos estadunidenses pasaron a vivir a México, pero pocos se adentraron en su vida, pues la mayoría se mantuvo en sus ghettos con sus clubs, escuelas e iglesias. También llegaron colonizadores, curiosamente grupos religiosos de mormones y menonitas que se establecieron en Chihuahua. Estos hechos significaron influencia cultural, aunque no muy importante, pues fue más la tecnológica. Hasta fines del porfiriato las ligas importantes entre los dos países fueron económicas, ya que las culturales dependían de Europa, sobre todo de Francia. El mismo positivismo francés de Comte que tanta influencia tendría en México iba a ser vencido por ideas francesas, sobre todo de Bergson.

El porfiriato había cambiado bastante al país haciéndole sufrir su primera modernización. La frontera, representación de autonomía y soberanía, era simbólica, ya que la gente pasaba a vivir de uno a otro lado sin trámites, y muchos niños mexicanos la cruzaban cada mañana para asistir a la escuela. En muchas ciudades del país, misioneros protestantes empezaban a cosechar jóvenes mexicanos, algunos de los cuales partieron a Estados Unidos a hacer estudios, de manera que ciertas ideas estadunidenses en boga entraron también a México. El anarquismo y el pensa-
3

5

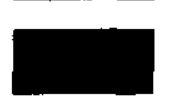


miento de Henry George y Bellamy influyó en el grupo de los Flores Magón; el progresivismo influyó en Madero; las ideas de control de la natalidad en Carrillo Puerto, y hubo resonancia de los muckraker socialist con la publicación del Barbarous México de John Kenneth Turner que denunciaba la explotación inicua que sufrían los indios en Yucatán.

Cuando estalló la revolución, los estadunidenses volvieron a dividirse en dos grupos, una mayoría adversa y una minoría simpatizante. Reporteros y camarógrafos se movilizaron a cubrir los frentes. John Reed, uno de ellos, enviado por el N.Y. World seguiría a Villa y de sus reportajes surgiría el libro Insurgent $\mathrm{Me}$ xico, publicado en 1914, donde pintaba a un hombre sin duda primitivo pero sincero, que hablaba de un triunfo en que no habría más ejércitos, y que lo único que hacía era lograr dictaduras, imagen que tal vez aseguró a Villa popularidad en Estados Unidos por algún tiempo.

Mas la industrialización en Estados Unidos también había creado cierta inquietud entre intelectuales y artistas que los empujaba hacia el exterior, en especial después dela desilusión de la primera guerra mundial. Franz Boas, desde 1908, había logrado interesar a instituciones de Europa y Estados Unidos y estableció la Escuela Internacional de Arqueología y Etnología en México en 1910, al tiempo que la Carnegie Institution empezaba a financiar las exploraciones arqueológicas del grupo de Sylvanns Morley. No todos simpatizaron con la revolución, e incluso al grupo de Morley se le acusó de hacer espionaje para su gobierno, pero casi todos los miembros de la "generación perdida" que en lugar de ir a Europa vinieron a México, la apoyaban. El tiempo era apropiado; la revolución entraba en su época de reconstrucción con un mi- nistro de Educación dispuesto a imprimir y regalar libros y a entregar y financiar muros en edificios públicos para que los pintores plasmaran sus mensajes e interpretaciones revolucionarias. Muchos artistas mexicanos volvieron junto con otros europeos curiosos lo que produjo durante los años veinte y treinta un ambiente excepcional para la cultura. Los artistas estadunidenses preocupados por la industria, encontraban en México el mundo de la artesanía, la espontaneidad y la inocencia y se forjaron libros como el de Frances Toor, A treasury of mexican folkways (1947) y Mexican life, asi como las exposiciones de arte popular organizadas por Roberto Montenegro y Adolfo Best Maugard. William Spratling describió Taxco y lo adoptó como residencia permanente, dedicando el resto de sus días a restaurar el viejo arte de la platería, del cual dejó testimonio en su libro My small mexican world.

Mexicanos y estadunidense colaboraron en muchas obras artísticas. Pablo O'Higgins y Diego Rivera pintaron murales en Chapingo y la SEP, Marion y Grace Greenwood en el mercado Abelardo Rodríguez, Siqueiros y Orozco en la Escuela Nacional Preparatoria, mientras Edward Weston y Tina Modoti tomaban testimonio fotográfico de todo aquel mundo junto al mexicano Luis Márquez.

Como ha escrito John Brown, las rentas, la comida y la bebida barata favorecieron la creatividad, de suerte que la vida cultural adquirió un brillo inusitado y reunió a grandes nombres como los estadunidenses Katherine Ann Porter, Hart Crawe, John Dos Passos, Waldo Frank, George Beddle, Stuart Chase, Susan Smith, Alma Reed, Archibald Mc Leisch, y los europeos Jean Chariot, Artaud, D. H. Lawrence y Somerset Maugham. La bohemia se puso a la orden del 
día y dio lugar a cuentos, novelas, poemas, ensayos. A. Mc Leish se empeñó en seguir a pie por el camino de Cortés y como producto de su aventura escribió uno de sus mejores poemas. George Beddle, cronista de aquel movimiento singular, escribió en su An american artist story (1939) que el muralismo mexicano era el movimiento más significativo desde el renacimiento, al reunir la belleza plástica y el mensaje de contenido social. Y el ejemplo mexicano le sirvió a Beddle para convencer a Roosevelt de que el gobierno estadunidense actuara como mecenas, de donde salió su proyecto de 1933.

La revolución no sólo atrajo a artistas y escritores; los antropólogos y arqueólogos los habían precedido y el profundo movimiento social interesó también a historiadores y estudiosos de las ciencias sociales, que en adelante se convertirían en constantes observadores y analistas de la escena mexicana. Algunos de los libros aparecidos entonces como Mexico an interpretation (1923) de Carleton Beals, The mexican agrarian revolution (1929) y Peace by revolution de Frank Tannenbaun y Tepotzotlan, a mexican village (1930) de Robert Redfield despertarian el interés por el país en todos los medios estadunidenses, especialmente académicos. Tannenbaun, como profesor, sembró en sus alumnos dicho interés, formando toda una generación de excelentes latinoamericanistas.

$\mathrm{Y}$ esto no fue todo, en otras áreas como la educación se sintió el influjo de estadunidenses. John Dewey influyó en la política educativa, tanto a través de su discípulo Moisés Sáenz, como a través de sus libros y conferencias. Los lingüistas William Cameron y Mauricio Swadesh serían piezas fundamentales en la for-

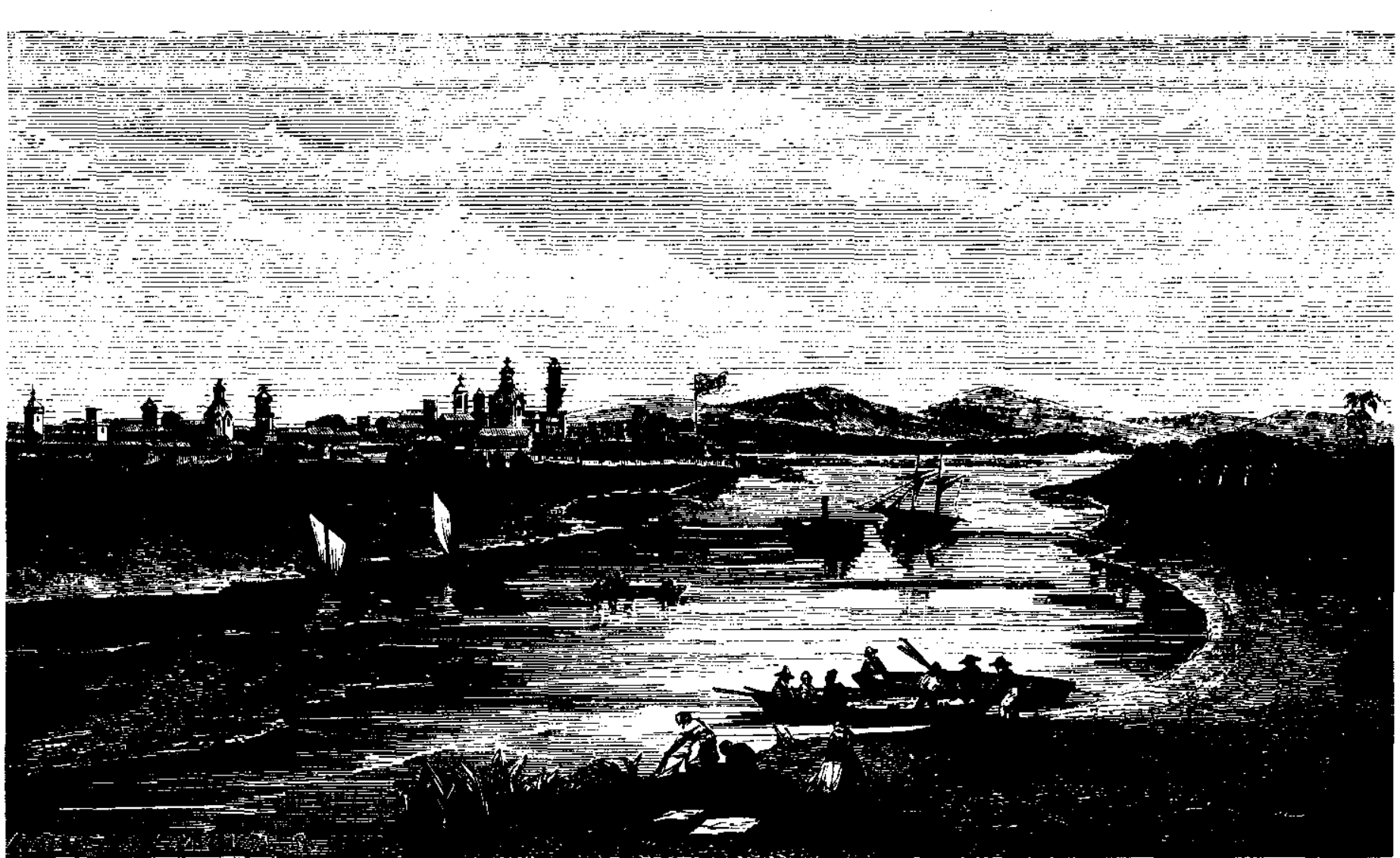




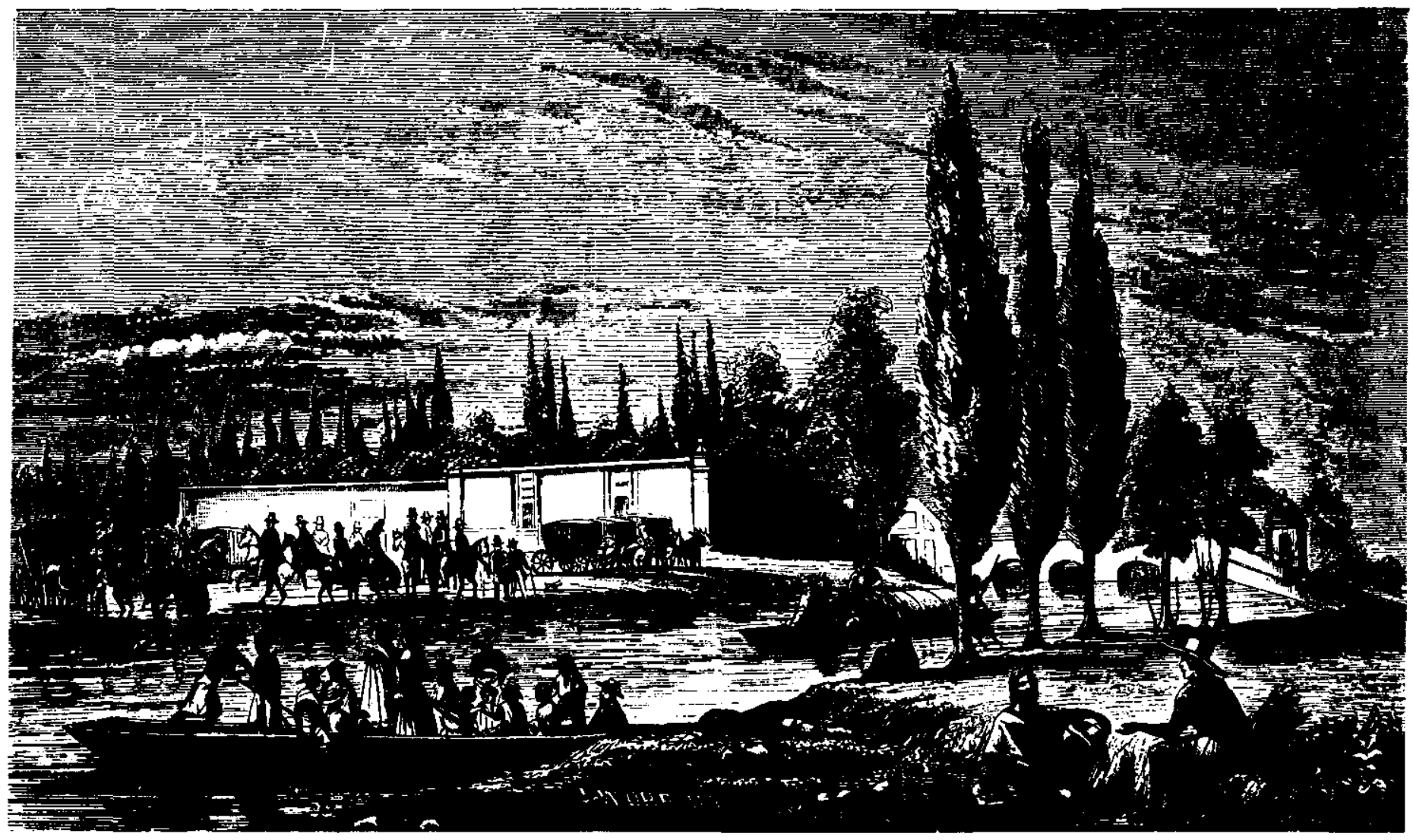

mación de lingüistas de ambos países, encargados de estudiar las 183 lenguas y dialectos hablados en el país. No obstante, la tarea no siempre fue benéfica, pues el Instituto Lingüistico de Verano tuvo connotaciones políticas y religiosas que provocan dudas serias.

La corriente no fluyó sólo de norte a sur; también en sentido contrario viajaron artistas, escritores, educadores y técnicos mexicanos. Orozco, Rivera, Covarrubias, Tamayo y hasta Siqueiros pasaron temporadas más o menos largas en Estados Unidos, casi siempre con éxito, al igual qủe los músicos Carlos Chávez que estudió en Nueva York en los años veinte y Blas Galindo y Pablo Moncayo que lo hicieron con Aaron Copland un poco más tarde. José Clemente Orozco hizo dos viajes, y en sus cartas a Jean Chariot y en su Autobiografia nos ha dejado un testimonio interesante y humorístico de sus experiencias en California, Nueva
York, Harlem y Darmouth, así como su traumático paso por Laredo donde un aduanero rompió todos sus dibujos por considerarlos "pornográficos".

¿Hasta qué punto toda la simpatía sembrada por los intelectuales estadunidenses modificólas ideas hostiles sembradas por la cadena Hearst? ¿Influyeron en la "política del buen vecino"? Es difícil contestar a esto, lo cierto es que, a pesar de la nacionalización del petróleo no se llegó a un rompimiento y que la segundà guerra mundial mejoraría las relaciones políticas. De nuevo los ideales declarados parecían coincidir y la retórica oficial hablaba no de América en el sentido de Estados Unidos sino en el continental. Mas la guerra impulsó la industrialización y la urbanización de México y era natural que los lazos y la influencia estadunidenses volvieran a estar dominados por la tecnología y la economía, como en tiempos de don Porfirio. México entraba 
lentamente, en parte, a una sociedad de masas, a ese incómodo estatus de contener todos los estadios culturales en sus entrañas.

El impacto estadunidense empezó a ser definitivo. Aunque de hecho se había iniciado antes pues, desde la primera guerra mundial, los cines en México proyectaban un $10 \%$ películas estadunidenses. El radio comercial, al establecer sus primeras estaciones, nació ligado a compañías publicitarias norteamericanas como la Colgate Palmolive, RCA, American Photo y El Águila. Pero más importante fue que la guerra hubiera absorbido una enorme cantidad de brazos mexicanos que, al regresar buena parte de ella a México, trajeran formas culturales, útiles o superfluas, que se advirtieron pronto en las poblaciones del norte y en otras como Irapuato, Zamora o León. De esa manera se introdujo, hasta el corazón mismo del país, una versión tardía del american dream que, junto a las limitaciones de oportunidad en el campo, produjo una emigración continua hacia el norte. Hay que subrayar el impacto conjugado de todos los medios de comunicación; su insistencia en el mensaje there is no way like the american way, (no hay un modo de vida mejor que el norteamericano) el Reader's Digest, el Life en español, los comics, las películas y la publicidad, colaboraron en una campaña que no dejó de ser dañina, en el sentido en que denigró muchas veces a otras formas de vida que ni siquiera comprendía.

El cine de los años cuarenta y cincuenta conquistó predominantemente a los jóvenes de entonces que hicieron ídolos a Glenn Miller, Tommy Dorsey, Bing Crosby, Frank Sinatra, Debbie Reynolds, etc., como luego los haría de Elvis Presley, Joan Baez y Pete Seeger. Por fortuna aquí, en amplias capas de la población, la música tropical y la ranchera dieron una buena batalla y aun se exportaron canciones y cantantes. En los años cuarenta y cincuenta empezó la conquista del mercado por parte de los productos estadunidenses como Kellog's y Gerber, los hot-dogs y las hamburguesas y al abrirse la primera cadena de supermercados en 1945 y los primeros Sears y Woolworth en 50 , se inició el camino hacia la sociedad de consumo.

Nuevas carreteras y líneas aéreas cada vez más baratas, transportaron una avalancha de turistas que no siempre fueron una bendición, aunque trajeron divisas. $\mathrm{Su}$ influencia se vio en todo, modas, lenguaje, hábitos. Pero nada sería tan decisivo en los cambios como la televisión comercial, que se inició en México en 1951, y que con gran falta de imaginación copió servilmente los programás de Estados Unidos, muchos de los cuales se retransmitieron simplemente a base de ratings estadunidenses. Esta es un ârea que ha preocupado hondamente a todos, y con mucha razón.

La tecnología ha jugado un papel importante en la influencia a vecesbuena, otras simplemente superflua, pero aparentemente inevitable. Las conexiones telefónicas automáticas y los satélites en los años setenta obligaron a México, tan cerca de los Estados Unidos, a mantener un ritmo que era artificial: una sociedad "en desarrollo" que copiaba patrones, aspiraciones y vicios de una sociedad posindustrial. Así en los sesenta vimos incluso reflejos de movimientos ajenos a nuestros problemas, como los hippies; importamos la moda de consumir marihuana en las clases medias y altas, cuando en México se usaba desde siempre en las capas bajas. Ahora era consumo de lujo. El enfrentamiento entre padres e hijos, tan típico de la fragmentación social posindustrial, se reflejó a causa del
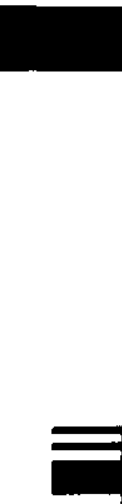


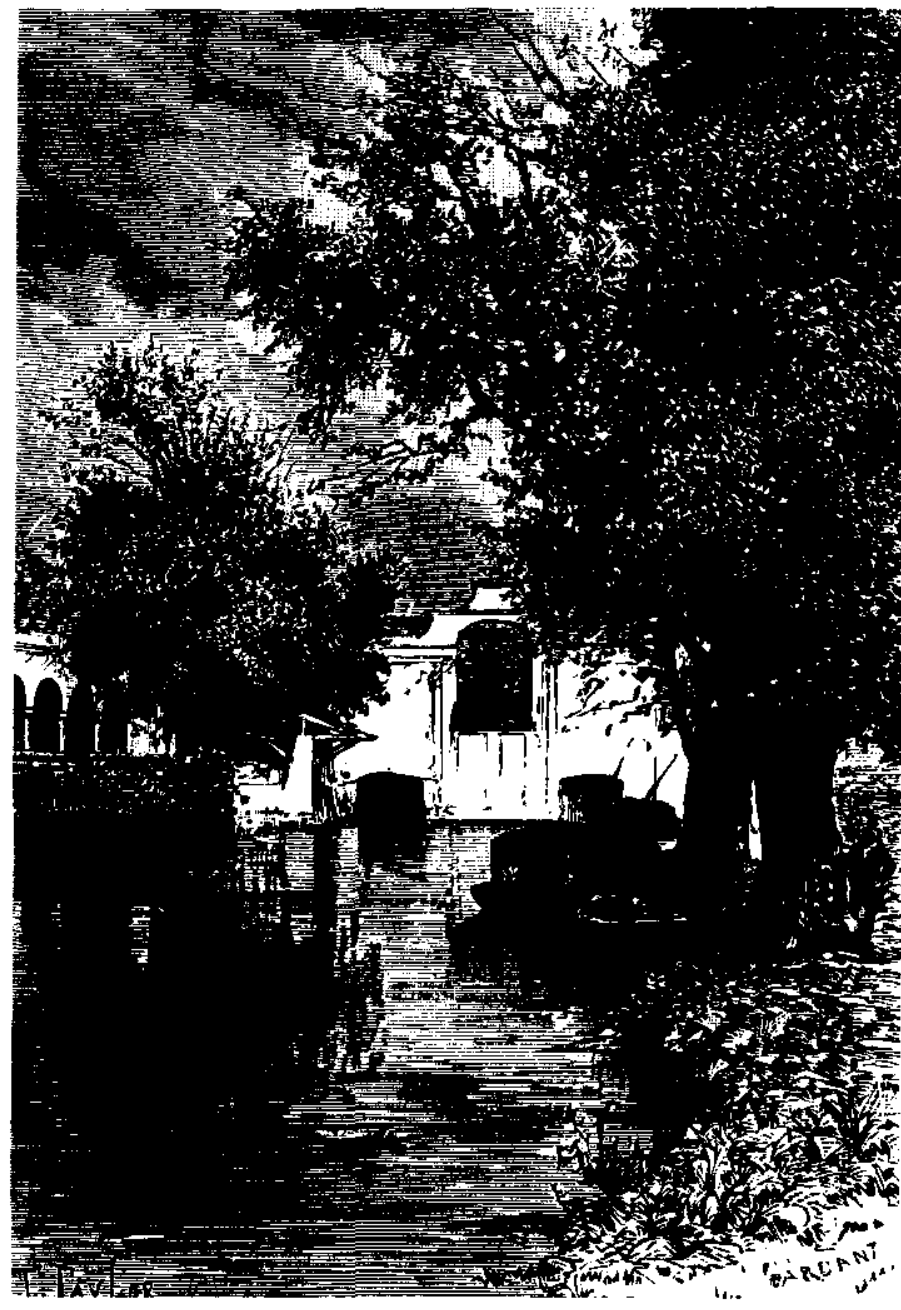

cine y la TV y las agencias noticiosas estadunidenses UPI y AP defendieron los estereotipos nacionales de buenos y malos de acuerdo con los intereses de Estados Unidos; primero, condenables japoneses y alemanes, después rusos, chinos, norcoreanos, norvietnamitas, etcétera.

La relativa influencia de los años setenta provocó que una amplia capa de mexicanos viajara a los lugares de sus "sueños". Disneylandia, Disney World, Macy's en Nueva York, La Galería en Houston, Las Vegas, Aspen. Sin mencionarque los jeans, las T-shirts, la música y los ritmos se importaron instantáneamente. Libros traducidos o en inglés también se leyeron con avidez, lo mismo el del doctor Spock que Cosmosy los libros de texto.

Time, Newsweek, PopularMechanics, Cosmopolitan, Buenhogar, Vanidades, complementan el panorama, junto a la televisión por cable y las estaciones retransmisoras de las cadenas de radio CBS o NRC. Esto resulta alarmante, y con la crisis hemos visto con cuánta razón, pues a veces la interpretación torcida de nuestros acontecimientos, como la que produjo el programa infame de $A B C$ de julio del 81, aumentó la salida de capitales mexicanos y detuvo el ingreso de miles de turistas causando gran daño al país. No obstante, también ha provocado que el mexicano, en general, se haya vuelto menos provinciano.

Esta influencia ha sido la más sobresaliente, aunque también hay que mencionar los lazos culturales a nivel de las altas manifestaciones del espíritu. Estudiantes y profesores, artistas y escritores, periodistas y técnicos han ido y venido constantemente. Antes de los años sesenta la vía norte-sur era la predominante, pero gracias a becas de las fundaciones, de los dos gobiernos y de las propias universidades, no sólo los mexicanos privilegiados estudian en Estados Unidos.

Entre los estadunidenses que viajan hacia el sur, predominan los estudiosos de las ciencias sociales, el arte y las humanidades $\mathrm{y}$, hasta muy recientemente, los mexicanos favorecían sobre todo a la ciencia y a la tecnología. Poco a poco, con la imposición de Nueva York como centro mundial del arte y las letras (y hasta de la moda y del jet-set), la afluencia de interesados en otras áreas ha aumentado. Para investigadores de humanidades y ciencias sociales existela atracción de grandes repositorios de documentos y libros entre los que destacan, además de la Biblioteca del Congreso y Pública de Nueva York, la Benson Latin American Library de la Universidad de Texas, la Bancroft de la Universidad de California y las bibliotecas Newberry y Huntington que han preservado tan- 

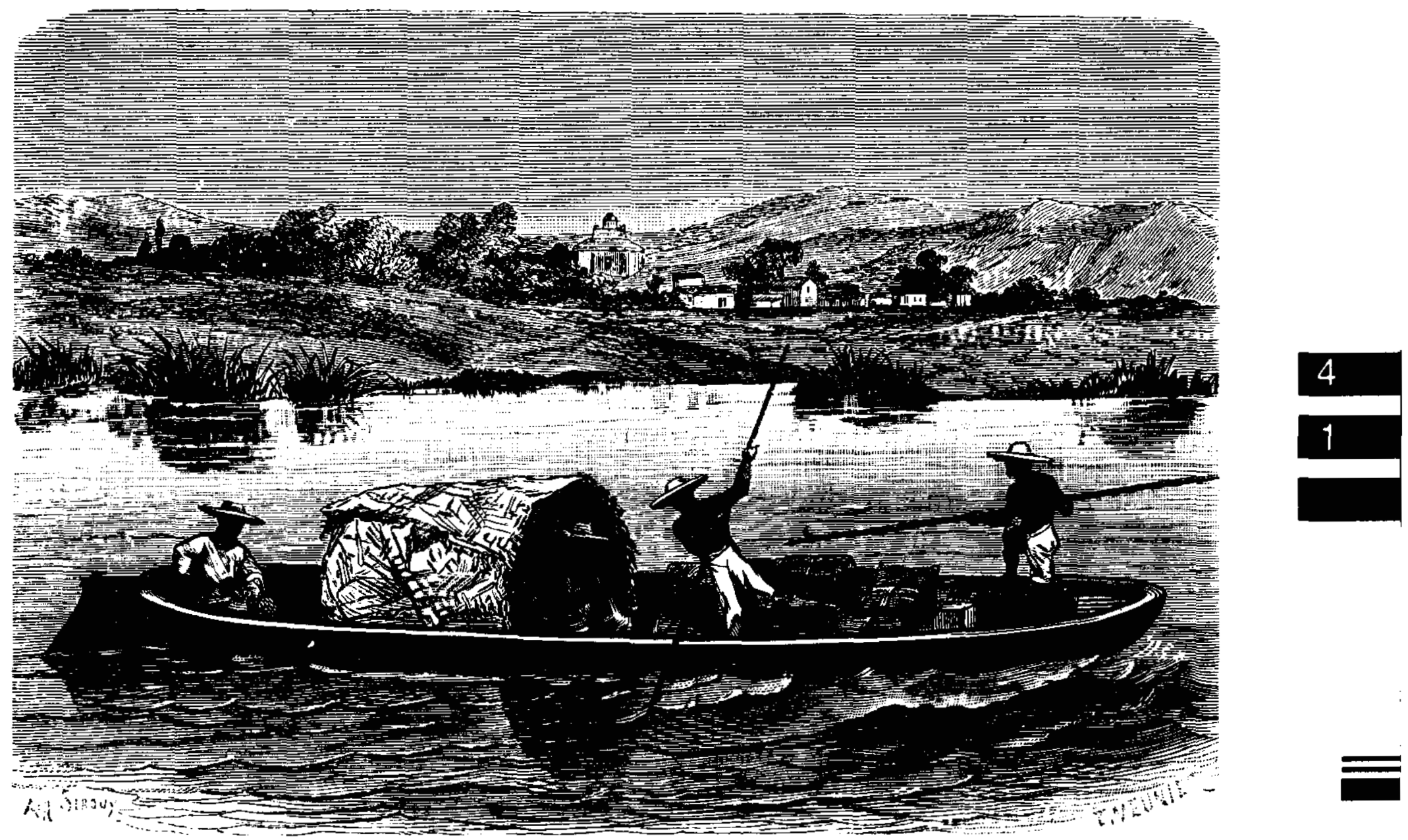

tos materiales sobre nuestro presente $y$ nuestro pasado.

Los estudios latinoamericanos no tuvieron una carrera fácil, como hizo notar alguna vez Lewis Hanke en su discurso como presidente de la American Historical Association (AHA), pero sin duda que se han establecido tan firmemente que incluso forman a gran parte de los latinoamericanistas latinoamericanos. Tal hecho se ha constituido en uno de los lazos de unión más firmes que existen. A través de investigaciones serias y dedicadas, de intercambio académico, de congresos y de reuniones ha florecido una colaboración cordial y acrítica que ha producido buenos frutos. Historiadores, literatos, científicos sociales y artistas han logrado, sin duda, mejorar la imagen de México, y en general de Latinoamérica, y han contribuido con su percepción diferente a completar el co- nocimiento de nuestra cultura, historia y problemás. Algunos libros como los de Redfield, Oscar Lewis, Frank Tannenbaun, Charles Gibson o John Womack Jr., (por señalar sólo algunos de los que han alcanzado una mayor difusión) han servido como inspiración para proseguir por las vías fijadas por ellos o contra ellos. Ya a fines de los años sesenta don Daniel Cosío Villegas afirmaba que era imposible estudiar el pasado o el presente de México sin saber inglés, pues para hacerlo se necesitaba leer las publicaciones estadunidenses e investigar en archivos y bibliotecas de Estados Unidos.

Es cierto que un alto grado de norteamericanización afecta áreas muy sensibles, pero era difícil que México fuera la excepción y, por otra parte, no hay que olvidar que también se ha extendido el área cultural mexicana en Estados Unidos. El intercambio extenso ha hecho que a la 
exportación de la hamburguesa y el hotdog corresponda la de los tacos y la enchilada.

Hemos importado las series "Dallas" y "Dinasty" y por desgracia "SesameStreet" y exportado "El presagio", "El chapulín colorado" y "El chavo del ocho". Esta expansión tiene que ver con el crecimiento de la influencia de los mexicanoamericanos e hispanoamericanos, pero también es una nueva sensibilidad de los estadunidenses que permite un mayor mercado para chiles, tortillas, amates y cerámica mexicana. No sólo eso, también se publican más traducciones literarias, se exponen más obras mexicanas $y$, con Eduardo Mata en la Orquesta Sinfónica de Dallas y Luis Herrera de la Fuente en Oklahoma, se populariza la música clásica mexicana. Embajadores culturales de la excelencia de Octavio Paz, Carlos Fuentes, Daniel Cosío Villegas, Silvio Zavala, Edmundo O'Gorman o Miguel León Portilla, quienes varias veces han dictado cátedra en Estados Unidos, también han creado ecos para nuestras preocupaciones. La cuestión seguirá estando en la diferencia cualitativa de los dos países y en que los mexicanos no olvidemos que somos ante todo un país, con muchos problemas y que debe elegir lo que realmente le conviene y no lo que simplemente aumenta sus gastos.

La cercanía con Estados Unidos nos fue impuesta por la geografía y por la historia. Nos causó uno de los traumas más profundos y su influencia es como la definía don Daniel Cosío ya en 1947: "como el Dios de los cristianos: omnipresente y omnipotente", pero también ha sido una fuente constante de definición de nuestra identidad, de enfrentarnos con valor con nosotros mismos. Claro que Carlos Fuentes tiene razón al preguntar si ha valido la pena adoptar un patrón de desarrollo al que cuestiona la sociedad misma que lo ha producido. También Carlos Monsivais la tiene al burlarse de la futilidad de la americanización de nuestras clases medias y altas que tan caras le resultan además al país. Don Daniel llamaba a estudiar bien a Estados Unidos como medida preventiva, para darnos cuenta no sólo de lo que es bueno y grande en la cultura estadunidense, sino también de los aspectos en que nosotros hemostenido suerte. Para mí, el punto clave está en reconsiderar y reducir nuestras aspiraciones, y no me refiero a las de consumo, que considero idiotas aquí y allá, sino a las de las finalidades como país. Enrique Krauze recordaba, con motivo de la crisis, cuánta razón parecía tener Tannenbaun en los años cuarenta al deplorar que México abandonara el mejoramiento del campo por la industrialización. Las aspiraciones perdieron todo sentido de la proporción y en la vida académica muchas vecesse ha importado loúltimo, sin preocuparse de que no hemos preparado los grupos medios que sostengan todo el aparato. Claro que necesitamos una elite que maneje los problemas con sofisticación, pero antes que importar modas necesitamos más que nada aumentar la responsabilidad y la calidad de todo lo que hacemos. No se trata de que hagamos comolos demás, sino de que inyectemos entusiasmo y enfrentemos con creatividad los terribles problemas que tenemos por delante.

La ambivalencia de admiración y temor que tienen los mexicanos ante Estados Unidos tiene que persistir, pues no en balde es elúnico país subdesarrollado junto a la potencia más grande del mundo. Pero si la crisis actual fuera una fuente de colaboración como lo fueron los años veinte y treinta, seguramente se fortalecerían los lazos que nos unen. 